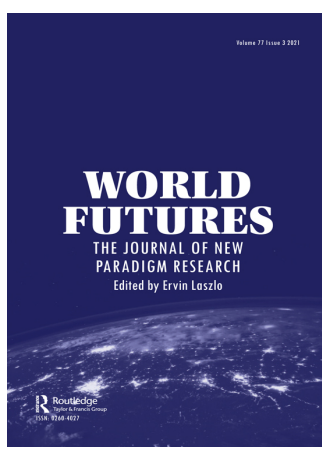

World Futures

The Journal of New Paradigm Research

ISSN: (Print) (Online) Journal homepage: https://www.tandfonline.com/loi/gwof20

\title{
The Morality of Carbon Offsets for Luxury Emissions
}

\section{Stearns Broadhead \& Adriana Placani}

To cite this article: Stearns Broadhead \& Adriana Placani (2021): The Morality of Carbon Offsets for Luxury Emissions, World Futures, DOI: 10.1080/02604027.2021.1969876

To link to this article: https://doi.org/10.1080/02604027.2021.1969876 (c) 2021 The Author(s). Published with
license by Taylor \& Francis Group, LLC.

曲 Published online: 29 Sep 2021.

Submit your article to this journal $\pi$

Q View related articles ¿

View Crossmark data 


\title{
The Morality of Carbon Offsets for Luxury Emissions
}

\author{
Stearns Broadhead (D) and Adriana Placani iD \\ University of Graz-Institute of Philosophy, Graz, Austria
}

\begin{abstract}
Carbon offsetting remains contentious within, at least, philosophy. By posing and then answering a general question about an aspect of the morality of carbon offsetting-Does carbon offsetting make luxury emissions morally permissible? - this essay helps to lessen some of the topic's contentiousness. Its central question is answered by arguing and defending the view that carbon offsetting makes luxury emissions morally permissible by counteracting potential harm. This essay then shows how this argument links to and offers a common starting point for further examination of offsetting across various disciplines and domains, such as policy and other branches of philosophy like the ethics of risk.
\end{abstract}

\section{KEYWORDS}

Carbon offsets; climate change; ethics of risk; harm; luxury emissions; moral permissibility; policy

\section{Introduction}

Carbon offsetting remains contentious within, at least, philosophy (Aldred, 2012; Caney, 2010; Goodin, 1994; Page, 2011, 2013; Watt, 2021). ${ }^{1}$ By posing and then answering a general question about an aspect of the morality of carbon offsetting-Does carbon offsetting make luxury emissions morally permissible? - this essay helps to lessen some of the topic's contentiousness. Its central question is answered by arguing and defending the view that carbon offsetting makes luxury emissions morally permissible by counteracting potential harm. This essay then shows how

CONTACT Stearns Broadhead stearns.broadhead@uni-graz.at Eniversity of Graz-Institute of Philosophy, Graz, Austria.

(C) 2021 The Author(s). Published with license by Taylor \& Francis Group, LLC.

This is an Open Access article distributed under the terms of the Creative Commons Attribution-NonCommercialNoDerivatives License (http://creativecommons.org/licenses/by-nc-nd/4.0/), which permits non-commercial re-use, distribution, and reproduction in any medium, provided the original work is properly cited, and is not altered, transformed, or built upon in any way. 
this argument links to and offers a common starting point for further examination of offsetting across various disciplines and domains, such as policy and other branches of philosophy like the ethics of risk.

This essay is organized in the following way. To help clarify the issues surrounding the morality of carbon offsetting, section "Preliminaries" briefly outlines and defines main topics and terms. Section "Defense" answers the central question by showing how carbon offsetting makes luxury emitting morally permissible. Section "Transdisciplinary applications" examines the ways this conclusion applies to disciplines and domains. A short conclusion ends this works.

\section{Preliminaries}

This work relies on Hyams and Fawcett's (2013) characterization of carbon offsetting as "a mechanism by which an organization or individual contributes to a scheme that is projected either to remove carbon dioxide from the atmosphere or to deliver carbon dioxide emission reductions on the part of other organizations or individuals" (91). Commonly, but not exclusively, emissions are offset through reforestation, afforestation, and emissions-capture projects (Dodds et al., 2012, p. 31). The typology of offsetting, broadly described here, includes two forms-regulatory and voluntary. Regulatory schemes allow organizations to comply with limits on carbon emissions through a regulatory carbon market (Gössling et al., 2007, p. 226). These schemes fall under the control of various regimes, such as the Kyoto Protocol and EU Emissions Trading Scheme (Corbera et al., 2009, p. 25-27). Voluntary schemes enable individuals to purchase and offset their personal CO2 emissions (Gössling et al., 2007, p. 227). As indicated at the outset, this work only focuses on voluntary offsetting.

The moral permissibility of carbon offsetting comes down to whether (something like) the following working thesis is true: it is sometimes morally permissible to do harm if that harm is offset by doing good. In other words, which describe offsetting in moral terms, doing good offsets doing or having done harm, and that good/harm calculus, when the good neutralizes or outweighs the harm, can permit an otherwise impermissible action.

It is worthwhile to consider the workings of moral offsetting generally even though this essay will not attempt to defend the moral permissibility of all possible examples of offsetting. Some moral theories, in at least caricatured forms, may commit their adherents to accepting very counterintuitive outcomes of what, on its face, appears to be offsetting. For example, as Judith Jarvis Thompson (1985, p. 1396) presented, the act consequentialist assents to vivisecting a homeless person if using the rescued organs would extend life to five others. This kind of apparently 
morally impermissible outcome highlights the need for restricting the breadth of the offsetting thesis.

Foerster (2019) presents three limiting conditions to offsetting (i.e. what counts as offsetting must meet these conditions), which will also guide the argument below. These conditions, by stipulation, must all be satisfied for doing good to offset doing harm. First, the Harm Condition-the harm is harm even when done in conjunction with the good-must obtain. Second, the Avoidability Condition-it is possible to do good without doing harm-must also obtain. Third, the Motivation Condition-the good is done to offset the harm-must obtain, too.

Let's look at Foerster's conditions in more detail, both to see the work they do and because they will be important for subsequent argument. The Harm Condition excludes cases that may putatively offset but are morally uninteresting. Foerster gives an example of soccer practice, where a parent drops off her child for soccer practice and picks up the child once practice is over (i.e. picking the kid up offsets an otherwise non-harming act of dropping the kid off).

The Avoidability Condition sifts out cases of doing harm from necessity in order to do good from those of (the morally questionable) offsetting, in which harm is avoidable but done with putatively counterbalancing good actions that follow. The Motivation Condition underscores that offsetting is not happenstance; rather, doing good is meant to counteract having done harm. In light of the three conditions, Thompson's example of the homeless person being sliced up for the benefit of saving others does not fit within the offsetting paradigm-the Motivation Condition does not obtain.

We can return to the topic of carbon offsetting for luxury emissions. For conceptual and terminological clarification, we rely on Henry Shue's (1993) oft-used distinction between luxury and subsistence emissions. Whereas subsistence emissions are "essential and even urgent for the fulfillment of vital needs," luxury emissions are "inessential for either survival or decency" $(1993,55)$. There are some straightforward instances of each sort (even considering debate about the distinction's exact boundaries and thresholds) (Baatz, 2014; Hayward, 2007; McLaughlin, 2019; Schlosberg, 2019). For example, subsistence CO2 emissions include those produced by a household when preparing hot food. ${ }^{2}$ A contrastive example of luxury emissions are those arising from taking a Sunday drive in a gas-guzzling SUV for no other reason or purpose than to "spin the wheels" or cruise around. ${ }^{3}$ Luxury emissions, then, do not comprise those necessary for securing vital needs.

The above examples do some work to illuminate the conceptual distinctiveness of these types of emissions. Perhaps the paradigmatic realworld examples of luxury emissions are those from leisure passenger air 
travel (Gössling et al., 2019, p. 2-5). Furthermore, many airlines, ticket services, and travel agencies offer carbon offsetting options, where passengers can pay to neutralize $\mathrm{CO} 2$ emissions from their respective shares of a flight's total CO2 emissions (Dodds et al., 2008). Although we return to these points later, it bears noting here that, among other reasons, air travel's major contributions to $\mathrm{CO} 2$ emissions coupled with its widespread availability and use spurs policy making as well as philosophical examination.

In addition to the above assumptions, we reject Walter SinnottArmstrong's view that luxury emissions from a lone individual's luxury emissions cannot tilt the balance enough to be consequential (SinnottArmstrong, 2005, p. 311). In other words, we claim that an individual's luxury emissions can contribute in a non-negligible or difference-making way to total $\mathrm{CO} 2$ emissions, such that they could potentially generate harm. Without this assumption, however, the discussion of the moral im/ permissibility of luxury emissions has no bite, with a knock-on effect for many instances of carbon offsetting-absent (potential) harm there are no grounds for offsetting. In this respect, the more challenging argument against carbon offsetting is to assume there is harm in individual luxury emissions.

Notice that while we assume this type of individual difference, the perspective has a substantial literature supporting it (Almassi, 2012; Gunnemyr, 2019; Hourdequin, 2010; Sandberg, 2011; Sandler, 2010; Zoller, 2015). The scope of this work does not allow for a complete argument in favor of this position, which is another reason to assume it. However, a brief defense is that, as John Broome notes, an average person from a rich country born in 1950 will emit around 800 tons in a lifetime (2012, p. 74). There are different ways to show the harmfulness of such individual emissions. Based on the World Health Organization's published estimates of the number of deaths and amount of disease that will be caused by global warming, Broome gives a rough estimate that an individual's lifetime emissions will wipe out more than six months of healthy human life (2012, p. 74). Other theorists, such as Nolt (2011) and Hiller (2011), also argue against the inconsequantialism of personal individual emissions on the basis of the very consequential harmful impact of individuals' personal emissions over the course of a lifetime or as derived from lifetime emissions.

There is an additional reason for assuming the above individual difference-making notion; namely, there is at least an intuitive conflict between luxury emitting and doing what is morally permissible. Sidestepping this sizeable discussion enables a more direct path to addressing whether one solution-carbon offsetting-can quell this intuitive conflict. 
Now, these preceding remarks (i.e. definitions, assumptions, explanation) highlight another assumption: carbon offsetting is an example of moral offsetting. Whether the argument below about carbon offsetting holds for or readily applies to other moral offsetting examples is not examined. Still, a lingering question remains vis-à-vis the morality of carbon offsetting; namely, what is being morally offset? Here, the assertion, which needs defending, is that a potential harm-the outcome of increased $\mathrm{CO} 2$ emissions-is offset (counteracted through reduction or nullification) by a countervailing removal of such emissions.

The countervailing good described above is assumed to be genuine. That is, it is assumed that the carbon offsetting scheme will in fact remove or prevent an increase in total $\mathrm{CO} 2$ emissions from the atmosphere (Broome 2012, Ch. 5). Furthermore, genuine, countervailing good assumes that any offsetting scheme instantiates principles of justice, such as those described by Caney (2010), McKinnon (2015), or Spiekermann (2014). Making this assumption about genuineness, including the principles of justice, does not weaken this work's core claim-carbon offsetting makes luxury emissions permissible-rather, it indicates a high bar that carbon offsets must reach in order to be permissible.

Taking the preceding remarks into account, the working thesis-it is sometimes morally permissible to do harm if it is offset by doing goodcan be amended. The thesis defended below is the following: it is morally permissible to luxury emit $\mathrm{CO} 2$ if such luxury $\mathrm{CO} 2$ emissions are counteracted by (genuine) carbon offsetting. Having identified the meaning of key terms, identified the basics of moral offsetting in general, announced assumptions that will carry forward throughout subsequent discussion, and refined the thesis to be defended, the next section is devoted to arguing for the position outlined.

\section{Defense}

The moral problem with carbon offsetting seems, at its root, to consist of the following dilemma: how can the harm of luxury $\mathrm{CO} 2$ emissions be counteracted by good such that luxury emitting is morally permissible? Some critics of offsetting cast the individual duty to do no (unnecessary) harm in terms of desisting from luxury emitting altogether. Rather than emit and equalize through offsets, an individual does not (luxury) emit at all. The desistance solution to emissions is, by all accounts, a morally permissible one; however, it does not conflict with or undermine the moral permissibility of offsetting. That is, not emitting is a better option, but it is an option that, in itself, cannot impugn the permissibility of carbon offsetting. 
What makes carbon offsetting (understood in qualified terms set out in the preceding section) permissible is that it does not increase an individual's contribution to total $\mathrm{CO} 2$ emissions. Consider a flyer, Passenger A, who purchases a carbon offset equal to the total $\mathrm{CO} 2$ emission tonnage for a third vacation flight in as many months from Buenos Aires to Caracas. This offset keeps Passenger A's total $\mathrm{CO} 2$ emissions equal to what they would have been had the flyer not flown at all. In other words, Passenger A makes no difference.

The above example is, by hypothesis, genuine and, as such, the duty to do no harm is met. This canceling effect, however, comes in for criticism (Goodin, 1994). Some criticism, as Julia Driver (2014) points out, arises from conflating otherwise distinctive wrongs. In contrast to intrinsic wrongs, such as disrespecting individual persons, carbon emissions are "instrumentally wrong since they generate harms" (Driver, 2014, p. 168). Above it was assumed that an individual's luxury emissions can but do not necessarily affect $\mathrm{CO} 2$ emission totals in a non-negligible way. They are harms to be avoided; however, they are not intrinsically wrong.

Contra arguments from Goodin (1994, p. 582), the carbon offset does not address an environmental wrong (putatively intrinsically wrong) through compensatory financial payment (i.e. an ill-matched remedy for the wrong produced). The carbon offset finances a means by which a (potential) wrong is counteracted. The difference is vital. Put simply, carbon offsets are not an economic side-constraint that, once paid, allow a user to pollute. Carbon offsets are a nullification of harm that a luxury emitter would otherwise cause or contribute to the cause. The negative outcome (harm and/or wrong) of an action (luxury emitting in its manifold forms) is avoided, rendering all things equal to the state of affairs before the luxury emission.

The strategy of defending the moral permissibility of carbon offsets for luxury emissions in general comes down to (a) the assumptions in the preceding section holding and (b) the stipulated limiting conditions of offsetting being met. In any a given example of carbon offsetting luxury emissions, such as Passenger A above, both (a) and (b) must obtain to be morally permissible. To answer the question that opened this section, then, the harm of luxury carbon emissions are morally permissible inasmuch as certain facts of given cases obtain to render such harm neutral. The instrumental (not intrinsic) wrongness of luxury carbon emissions is also amongst those facts.

The sequence of events also matters. The defensibility of luxury emissions as morally permissible turns in part on offsetting counteracting expected harm, rather than remedying harm that has occurred. In this respect, doing no harm comes about through prophylactically countering harm that luxury emitting may generate. As discussed above, but worth mentioning here again, 
such prophylactic measures would not work for intrinsic wrongs-in rather absurd terms, giving birth to a human being does not offset killing another human being, prophylactically or otherwise.

A legitimate challenge to this defense of offsetting's permissibility is that carbon offsets only imperfectly account for harm (Kamm, 2006). Consider an iteration of this imperfect correspondence: Passenger A's flight from Buenos Aires to Caracas contributes to an increase in asthma cases of those persons living under its flight path. The resolution to this sort of imperfect correspondence case, where carbon offsetting only counteracts one sort of harm (of which there are multiple), is that some activities may be impermissible for other reasons (Lawford-Smith and Tuckwell, 2020, p. 5). Carbon offsetting is meant to counteract the harm associated with climate change.

Notice that this sort of case does not represent a mark against carbon offsetting since the offsetting is presumed to deliver on its reduction promise. It may, however, represent a mark against a practice that increases a variety of other risks, only some of which carbon offsetting counteracts. This defense is contingent on the practice in question-luxury emitting by flying or taking a Sunday drive or burning coal when less-emission-producing alternatives are available, etc. However, such contingency underscores (when it does) that ensuring moral permissibility by means of carbon offsetting has its limits. This tracks common sense moral intuitions. Carbon offsetting is not an appropriate corrective, nor does offsetting make this permissible.

\section{Transdisciplinary Applications}

This section highlights how the philosophical argument for the moral permissibility of carbon offsetting luxury emissions applies to other disciplines and domains. In other words, it illuminates possible applications of the main philosophical argument and identifies some of its transdisciplinary breadth. Given this work's scope, it is impossible to set out anything nearing a complete taxonomy of such domains. This section instead focuses on two areas in which there is apparent applicability-policy and other philosophical topics. To highlight the cross-cutting features of this essay's central argument and conclusion (and related issues), this section underscores how policy and the ethics of risk can use and possibly extend the argument.

Developing and implementing policy for offsetting luxury emissions is complex. Among other things, it requires attention to the various features and assumptions that make carbon offsetting morally permissible in the first place. The complexities of carbon offsetting policy are markedly 
similar to those that attend policy making and implementation generally, as well as environmental policy specifically.

Policy must contend with foundational philosophical issues-such as whether there is an ethical case for carbon offsetting, which the above discussion and argument shows there is (Wolff, 2011, p. 4-7). Such issues also include assessing empirical details about if and how particular offsetting schemes achieve requisite conditions and desired effects (e.g. genuine neutralization of CO2 emissions) (Weale, 2019, p. 51-53). In addition, they include legal facts about policy makers and their powers (whether national, supranational, international, or otherwise), as well as democratic legitimacy (Howard, 2019). The policy challenges of carbon offsetting, then, include but do not stop at philosophical problems. However, conforming to the core argument about the moral permissibility of carbon offsetting luxury emissions is a sine qua non of any policy (Howard, 2019, p. 32-33). Furthermore, as we see it, this essay's central argument helps to justify the inclusion of offsetting as an option for policies aimed at mitigating climate change.

Within policy, carbon offsetting is also to be considered in terms of efficacy, efficiency, and alternative options. Such alternatives may deliver better results-for example, reducing other possible harms or more efficiently achieving a policy goal. The empirical issues link back to and potentially expose yet other philosophical issues to address (Weale, 2019, p. 51-53). In this sense, what is morally permissible-carbon offsetting luxury emissions-might not be morally preferable when considering a wider range of benefits and burdens following from other, non-offsetting policy options.

Consider a real-world instance, such as Article 36 of 2021 national legislation in France designed to combat climate change and strengthen resilience to its effects. ${ }^{4}$ To reduce $\mathrm{CO} 2$ emissions, Article 36 bans domestic flights of less than two-and-a-half hours long that are serviced by train connections (with comparable pricing to flights). One way to view Article 36 is that France's National Assembly opted to eliminate $\mathrm{CO} 2$ emissions rather than require them to be offset. That is, the legislation bans flights even though enacting carbon offsetting policy measures would presumably yield equivalent results vis-à-vis luxury emissions (and subsistence emissions as well).

Let's look at some of the complications of carbon offsetting in such a policy. First, as previously noted, other possible harms generated are reduced through the flights' elimination. Furthermore, inequities that carbon offsets might abet, depending on their pricing, would be avoided. If flights become so expensive because of offsetting costs, making them purchasable by relatively few wealthy individuals, then the burden of this policy could outweigh its benefits. Also, quite simply, halting all domestic 
flights of less than two-and-a-half hours may more efficiently reduce $\mathrm{CO} 2$ emissions than carbon offsets and thereby more greatly benefit the public good. Notice that even if banning flights proves more efficient in the Article 36 defined use case, carbon offsets could still play an important complementary role-for example, as an option offered for leisure train travel, or possibly even a requirement of leisure train travel. In this way, additional carbon neutralization could be achieved.

None of the above affects the argument establishing the morality of carbon offsetting. Furthermore, the viability of offsetting as one tool to combat climate change is potentially heightened when used in a complementary approach to neutralize emissions (i.e. with other mitigation measures). Ultimately, what policy must contend with is not determining whether carbon offsetting in theory is morally permissible, but rather how to ensure that it achieves needs and goals whilst remaining morally permissible in practice. This opens additional lines of research to be investigated.

From the vantage point of other philosophical topics, carbon offsetting and offsetting generally open novel possibilities for addressing thorny problems. The central argument of this work exclusively focuses on a question about the morality of carbon offsetting for luxury emissions; however, emissions generally increase a variety of risks to the environment and health, among other things. The ways in which offsetting can help solve and tackle such risks, at least with respect to their philosophical dimensions, most evidently falls under the purview of the ethics of risk.

Defined canonically, the ethics of risk is the "branch of moral philosophy that enquires into the principles that should morally guide choice in circumstances where the outcome of some possible course of action is not known" (Altham, 1984, p. 15). A central challenge within the ethics of risk is how to cope with risk not simply as "an 'unfortunate aspect' of contemporary social life, but a fundamental empirical circumstance of any society, present and future" (Erman \& Möller, 2018). There is need to guide individual (and collective) action in ways that ameliorate unwanted risks. The full range of possible applications of offsetting, explored in terms of their moral appeal and appropriateness, may help to fill that need.

Offsetting does not seem designed or capable to answer the full array of challenges of pervasive risk in society (one could, however, devise plausible arguments indicating otherwise). It nevertheless represents a means of negating at least some potential harms, luxury emission-caused and otherwise. Offsetting can be considered in light of its potential to reduce negative results that may follow from deciding and acting under conditions of uncertainty. The hypothesis to be investigated, then, is that 
offsetting provides a possible avenue for prophylactically counteracting negative results from risky decisions and actions (e.g. emitting). Furthermore, how offsetting fits into a larger moral theory-utilitarian, contractualist, deontological, etc.- to help meet the challenge of risks is another area for examination (Foerster, 2019, p. 6-12).

A viable aim for the ethics of risk would be to integrate offsetting into a wider theory of how to address risk through principles for action guidance. The key point here is that offsetting may play a role in filling gaps presented by risks. The narrower argument about the moral permissibility of carbon offsetting not only enables consideration of offsetting as a practicable solution in other domains, but it also highlights that those other domains may be much more widespread than just that of carbon offsetting. Policy and the ethics of risk are just two domains considered; however, their far-reaching impact at least highlights the extent to which offsetting may go if fully integrated. Again, the common starting point for any discipline to integrate offsetting is its standing as a morally permissible solution to (potential) harms, even if it might not always be the morally preferable solution.

\section{Conclusion}

The preceding argument and defense highlights how an individual may avoid doing harm in luxury emitting through carbon offsetting. The moral permissibility of luxury emitting turns on a number of facts, in absence of which there is reason to doubt the permissibility of luxury emitting. The ground this argument clear is debates about whether it is ever morally permissible to luxury emit. Removing some or all of the assumptions and stipulations from this defense of the moral permissibility of luxury emissions through carbon offsets could render luxury emissions impermissible tout court, as some argue. However, identifying a basic means by which luxury emissions are permissible draws a bright line around any voluntary offsetting schemes. These schemes must reach a high bar (of genuineness, justice, and so on) to be deemed morally permissible alternatives to desisting luxury emissions altogether. Taking all of this into account, the extension and application of the argument's conclusion to other disciplines and domains opens novel possibilities for addressing pernicious societal problems in theory and practice.

\section{Notes}

1. See this brief list of philosophical treatments (or analyses with philosophical considerations included): (Aldred, 2012; Caney, 2010; Goodin, 1994; Page, 2011, 2013; Watt, 2021). 
2. See this list (though not exhaustive) from Qu et al. (2013), where subsistence $\mathrm{CO} 2$ emissions are "the necessary emissions from the fundamental consumption of the household, including the $\mathrm{CO} 2$ emissions due to use of coal, LPG, gasoline and diesel oil, and the $\mathrm{CO} 2$ emissions from the production, transportation and service processes of goods and services, such as electricity, food, clothing, medicine and medical care subsistence CO2 emissions."

3. Qu et al. (2013) also provide a list of luxury emissions (from households); they are "CO 2 emissions due to the consumption of education, recreation, transportation and communication services."

4. See Project de Loi, portant lutte contre le dérèglement climatique et renforcement de la résilience face à ses effets [Bill to combat climate change and build resilience to its effects], $\mathrm{N}^{\circ}$ 3875, Assemblée Nationale de la République Française, February 10, 2021. https://www.assemblee-nationale.fr/ dyn/15/dossiers/lutte_contre_le_dereglement_climatique?etape=15-AN1-

DEPOT. This bill is sometimes simply referred to as the Climate Law or Climate Bill, and it consists of 126 articles aimed at reducing CO2 emissions and improving the environment, among other things.

\section{Acknowledgments}

The authors thank the anonymous reviewer for comments and suggestions. This article was written as part of the research project Responsibility for Risks: Theory and Practice.

\section{Funding}

The authors gratefully acknowledge financing from the Austrian Science Fund (FWF): project number P-31527.

\section{ORCID}

Stearns Broadhead (D) http://orcid.org/0000-0002-6691-8928

Adriana Placani (D) http://orcid.org/0000-0002-3772-2571

\section{References}

Aldred, J. (2012). The ethics of emissions trading. New Political Economy, 17, 339-360.

Almassi, B. (2012). Climate change and the ethics of individual emissions: A response to Sinnott-Armstrong. Perspectives: International Postgraduate Journal of Philosophy, 4, 4-21.

Altham, J. (1984). Ethics of risk. Proceedings of the Aristotelian Society, 84(1), 15-29. https://doi.org/10.1093/aristotelian/84.1.15

Baatz, C. (2014). Climate change and individual duties to reduce GHG emissions. Ethics, Policy \& Environment, 17(1), 1-19. https://doi.org/10.1080/21550085. 2014.885406

Broome, J. (2012). Climate matters: Ethics in a warming world. W.W. Norton. 
Caney, S. (2010). Markets, morality and climate change: What, if anything, is wrong with emissions trading? New Political Economy, 15(2), 197-224. https:// doi.org/10.1080/13563460903586202

Corbera, E., Estrada, M., \& Brown, K. (2009). How do regulated and voluntary carbon-offset schemes compare? Journal of Integrative Environmental Sciences, 6(1), 25-50. https://doi.org/10.1080/15693430802703958

Dodds, R., Leung, M., \& Smith, W. (2008). Assessing awareness of carbon offsetting by travelers and travel agents. Anatolia, 19(1), 135-148. https://doi.org/10. 1080/13032917.2008.9687058

Dodds, R., Kelman, I., Thiesen, N., McDougall, A., Garcia, J., \& Bessada, T. (2012). Industry perspectives on carbon-offset programs in Canada and the United States. Sustainability: Science, Practice and Policy, 8(2), 31-41. https:// doi.org/10.1080/15487733.2012.11908094

Driver, J. (2014). Moral bookkeeping, consequentialism, and carbon offsets. In A. Hiller, R. Ilea \& L. Kahn (Eds.), Consequentialism and Environmental Ethics (pp. 164-173). Routledge.

Erman, E., \& Möller, N. (2018). The interdependence of risk and moral theory. Ethical Theory and Moral Practice, 21(2), 207-216. https://doi.org/10.1007/ s10677-018-9881-y

Foerster, T. (2019). Moral offsetting. The Philosophical Quarterly, 69(276), 617-635. https://doi.org/10.1093/pq/pqy068

Goodin, R. E. (1994). Selling environmental indulgences. Kyklos, 47(4), 573-596. https://doi.org/10.1111/j.1467-6435.1994.tb02067.x

Gössling, S., Hanna, P., James Higham, J., Cohen, S., \& Hopkins, D. (2019). Can we fly less? Evaluating the 'necessity' of air travel. Journal of Air Transport Management, 81, 101722-101710. https://doi.org/10.1016/j.jairtraman.2019.101722

Gössling, S., Broderick, J., Upham, P., Ceron, J-P., Dubois, G., Peeters, P. \& Strasdas, W. (2007). Voluntary carbon offsetting schemes for aviation: Efficiency, credibility and sustainable tourism. Journal of Sustainable Tourism, 15(3), 223-248. https://doi.org/10.2167/jost758.0

Gunnemyr, M. (2019). Causing global warming. Ethical Theory and Moral Practice, 22, 399-424.

Hayward, T. (2007). Human rights versus emissions rights: Climate justice and the equitable distribution of ecological space. Ethics \& International Affairs, 21(4), 431-450. https://doi.org/10.1111/j.1747-7093.2007.00117.x

Hiller, A. (2011). Climate change and individual responsibility. The Monist, 94(3), 349-368. https://doi.org/10.5840/monist201194318

Hourdequin, M. (2010). Climate, collective action and individual ethical obligations. Environmental Values, 19, 443-464.

Howard, J. (2019). The public role of ethics and public policy. In A. Lever \& A. Poama (Eds.), The Routledge Handbook of Ethics and Public Policy (pp. 25-36). Routledge.

Hyams, K., \& Fawcett, T. (2013). The ethics of carbon offsetting. Wiley Interdisciplinary Reviews: Climate Change, 4(2), 91-98. https://doi.org/10.1002/ wcc. 207

Kamm, F. M. (2006). Intricate Ethics. Oxford UP.

Lawford-Smith, H., \& Tuckwell, W. (2020). Act consequentialism and the no-difference challenge. In Douglas W. Portmore (Ed.), The Oxford Handbook of Consequentialism. Oxford UP. 
McLaughlin, A. (2019). Justifying Subsistence Emissions, Past and Present. The British Journal of Politics and International Relations, 21(2), 263-269. https:// doi.org/10.1177/1369148119830015

McKinnon, C. (2015). Climate justice in a carbon budget. Climatic Change, 133(3), 375-384. https://doi.org/10.1007/s10584-015-1382-6

Nolt, J. (2011). How harmful are the average American's greenhouse gas emissions? Ethics, Policy and Environment, 14(1), 3-10. https://doi.org/10.1080/ 21550085.2011.561584

Qu, J., Zeng, J., Li, Y., Wang, Q., Maraseni, T., Zhang, L., Zhang, Z., \& ClarkeSather, A. (2013). Household carbon dioxide emissions from peasants and herdsmen in northwestern arid-alpine regions, China. Energy Policy, 57, 133-140. https://doi.org/10.1016/j.enpol.2012.12.065

Page, E. A. (2011). Cashing in on climate change: political theory and global emissions trading. Critical Review of International Social and Political Philosophy, 14(2), 259-279. https://doi.org/10.1080/13698230.2011.529713

Page, E. A. (2013). The ethics of emissions trading. Wiley Interdisciplinary Reviews: Climate Change, 4(4), 233-243. https://doi.org/10.1002/wcc.222

Sandberg, J. (2011). My emissions make no difference: Climate change and the argument from inconsequentialism. Environmental Ethics. 33, 229-248.

Sandler, R. (2010). Ethical theory and the problem of inconsequentialism: Why environmental ethicists should be virtue-oriented ethicists. Journal of Agricultural and Environmental Ethics, 23,167-183.

Schlosberg, D. (2019). Further uses for the luxury/subsistence distinction: Impacts, ceilings, and adaptation. The British Journal of Politics and International Relations, 21(2), 295-302. https://doi.org/10.1177/1369148118819065

Shue, H. (1993). Subsistence emissions and luxury emissions. Law \& Policy, 1, 39-59.

Sinnott-Armstrong, W. (2005). It's not my fault. In W. Sinnott-Armstrong \& R. Howarth (Eds.), Perspectives on Climate Change: Science, Economics, Politics, Ethics (pp. 285-307). Emerald.

Spiekermann, K. (2014). Buying low, flying high: Carbon offsets and partial compliance. Political Studies, 62(4), 913-929. https://doi.org/10.1111/1467-9248. 12044

Thompson, J. J. (1985). The trolley problem. Yale Law Journal, 94, 1395-1415.

Watt, R. (2021). The fantasy of carbon offsetting. Environmental Politics, 1-20.

Weale, A. (2019). Public policy and normative methods. In A. Lever \& A. Poama (Eds.), The Routledge Handbook of Ethics and Public Policy (pp. 51-61). Routledge.

Wolff, J. (2011). Ethics and public policy: A philosophical inquiry. Routledge.

Zoller, D. (2015). Moral responsibility for distant collective harms. Ethical Theory and Moral Practice, 18, 995-1010. 